\title{
Lysozyme Lysis of Gram-Negative Bacteria without Production of Spheroplasts
}

\author{
By J. G. VOSS \\ Research Division, Miami Valley Laboratories \\ The Procter \& Gamble Company, Cincinnati, Ohio, U.S.A.
}

(Received 29 November 1963)

\section{SUMMARY}

Cells of Gram-negative bacteria undergo lysis when treated with lysozyme in the presence of ethylenediaminetetraacetic acid (EDTA) and tris buffer, as shown by Repaske. However, contrary to the prevalent assumption, lysis is not necessarily preceded by formation of a spheroplast as the cell wall is damaged. Treatment of Escherichia coli and Pseudomonas aeruginosa with the lytic system was shown to cause the formation of osmotically fragile rods, rather than spheres. The extent of destruction of the cell walls of Gram-negative bacteria by lysozyme in this system is, at least in some cases, less than has been generally supposed.

\section{INTRODUCTION}

Spheroplasts have been described by Tulasne, Minck, Kirn \& Krembel (1960) and McQuillen (1960) as spherical bodies formed after partial loss of the bacterial cell wall; they are osmotically fragile, and undergo lysis in media of low osmotic pressure. Protoplasts, on the other hand, are characterized by complete loss of the cell wall (Brenner et al. 1958; McQuillen 1960).

Repaske (1956, 1958) demonstrated that the cells of a number of unrelated species of Gram-negative bacteria could be lysed by lysozyme, in the presence of ethylenediaminetetraacetic acid (EDTA) with tris buffer (tris-(hydroxymethyl) aminomethane) at pH 8. This system was used (Mahler \& Fraser, 1956; Fraser \& Mahler, 1957) to prepare 'protoplasts' or spheroplasts of Escherichia coli in the presence of $0.5 \mathrm{M}$-sucrose. Although none of these papers reported any morphological observations on the transformation of cells to spheroplasts, McQuillen (1958) stated that '... Repaske [has] used lysozyme, to prepare spherical, osmotically shockable forms of Gram-negative bacteria such as Escherichia coli'. Later, McQuillen (1960) said, 'Mahler and Fraser went on to show that in the case of $E$. coli lysis could be prevented and the action arrested at a stage of spherical, osmotically shockable "protoplasts" if sucrose $(0.5 \mathrm{M})$ were present'.

It is the purpose of this communication to demonstrate that treatment of Gramnegative bacteria with the lysozyme-EDTA-tris buffer system may yield osmotically fragile cells, without so complete a destruction of the rigid cell wall as to cause the production of true spheroplasts. 


\section{METHODS}

The organisms used were Escherichia coli (ATCC 10536) and a strain of Pseudomonas aeruginosa isolated in our laboratories. Twenty-four hour cultures at $37^{\circ}$ in brain heart infusion broth (Difco) were centrifuged, washed twice with water, and resuspended in half the original volume of water. Optical densities at $660 \mathrm{~m} \mu$ were about $0 \cdot 65$ and $0 \cdot 25$, respectively, as measured with a Coleman Junior Spectrophotometer and $16 \mathrm{~mm}$. test tubes.

EDTA was used as the disodium salt. A $1 \%$ solution was adjusted to $\mathrm{pH} 8.0$ before use. Tris buffer was prepared as a $1 \mathrm{~m}$ solution, adjusted to $\mathrm{pH} \mathrm{8.0} \mathrm{with} \mathrm{HCl}$. Crystalline egg white lysozyme (Difco) was dissolved in distilled water to give a concentration of $1 \mathrm{mg} . / \mathrm{ml}$.

For studies of lysis, a $2 \mathrm{ml}$. portion of the suspension of washed cells of Escherichia coli was exposed to $500 \mu \mathrm{g}$. EDTA and $20 \mu \mathrm{g}$. lysozyme $/ \mathrm{ml}$., in the presence of $0.033 \mathrm{M}$-tris buffer and in a total volume of $6 \mathrm{ml}$. For Pseudomonas aeruginosa, the concentration of EDTA was reduced to $200 \mu \mathrm{g}$. $/ \mathrm{ml}$.; other conditions remained the same. Lysis at room temperature was followed by measurement of optical density at $660 \mathrm{~m} \mu$, as above.

For studies of morphological changes occurring during the action of lysozyme, parallel studies were carried out in the presence of $0.5 \mathrm{M}$-sucrose to prevent lysis. As controls, cell suspensions were prepared with sucrose alone, or with the EDTAtris buffer-sucrose systems without lysozyme. After standing for $20 \mathrm{~min}$., $3 \mathrm{ml}$. samples of each suspension were treated with 6 drops of $10 \%$ formaldehyde or 1.5 ml. of $1 \%$ buffered osmic acid fixative (Chapman, 1959) and allowed to stand overnight. The fixed cells were then washed three times in distilled water, diluted, and a specimen deposited on a carbon substrate and shadowed with platinum before examination in a Siemens Elmiskop I electron microscope.

\section{RESULTS}

The curves in Fig. 1 show the lysis of Escherichia coli and Pseudomonas aeruginosa upon exposure to lysozyme in the presence of EDTA and tris buffer, under the conditions outlined above. In each case, turbidity of the suspension decreased 70 to $75 \%$ during $10 \mathrm{~min}$. at room temperature. Microscopic examination after this period showed only amorphous debris.

However, when the presumed 'spheroplasts' derived from treatment with lysozyme-EDTA-tris buffer were supported with sucrose to prevent lysis, and fixed with osmic acid or formaldehyde, examination with the electron microscope showed that spheres had not, in fact, been formed. In Pl. 1, the first three figures show the appearance of Escherichia coli after exposure to sucrose alone (Pl. 1, fig. 1), EDTAtris buffer-sucrose (Pl. 1, fig. 2), and lysozyme-EDTA-tris buffer-sucrose (Pl. 1, fig. 3). In comparison with the normal cell (Pl. 1, fig. 1), that exposed to the lytic system (Pl. 1, fig. 3) shows evidence of extensive loss of internal substance and damage to the cell wall, but still retains its identity as a rod. Organisms treated with EDTA and tris buffer alone, in the presence of sucrose (Pl. 1, fig. 2), also show some evidence of damage, as compared with the normal.

With Pseudomonas aeruginosa, similar findings were obtained. Plate 1, figs. 4, 5 
and 6, show the results of corresponding treatments of this organism, and reveal that here, too, conversion of the bacteria to an osmotically fragile form by treatment with lysozyme-EDTA-tris buffer is not accompanied by transformation of the rods to spheres. Both the mixture of EDTA with tris buffer and the system with lysozyme caused less obvious morphological damage to $P$. aeruginosa than to Escherichia coli.

The osmotic fragility of both species after exposure to the lytic system was confirmed by dilution; lysis occurred rapidly on the addition of three or four volumes of water.

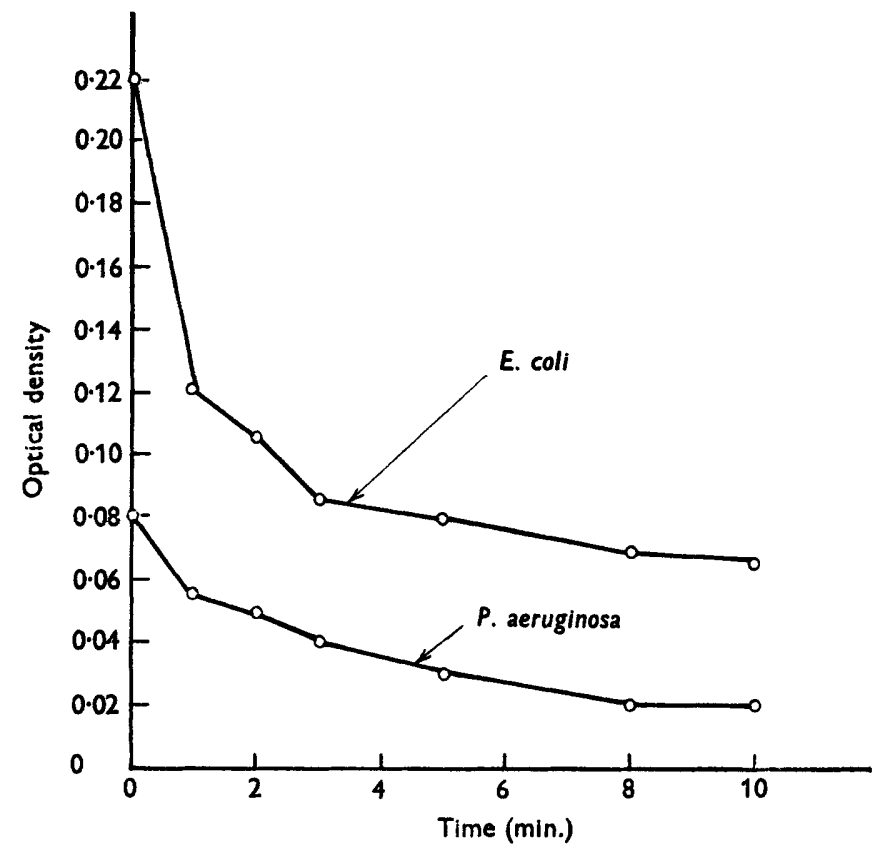

Fig. 1. Decrease in optical density at $660 \mathrm{~m} \mu$ of suspensions of Escherichia coli and Pseudomonas aeruginosa in the presence of $500 \mu \mathrm{g}$. EDTA $/ \mathrm{ml}$. (E. coli) or $200 \mu \mathrm{g}$. EDTA/ml. (P. aeruginosa), 0.083 k-tris buffer, and $20 \mu \mathrm{g}$. lysozyme/ml.

\section{DISCUSSION}

That lysozyme can cause the conversion of Gram-negative bacteria to spheroplasts has been demonstrated by Zinder \& Arndt (1956), who illustrated the formation of spheroplasts of Escherichia coli by lysozyme at pH 9. It has been generally assumed that the production of lysis of Gram-negative bacteria by similar means must be preceded or accompanied by the destruction of so much of the rigid cell wall that the rods are converted to spheres. McQuillen $(1958,1960)$ assumed that Repaske and Mahler \& Fraser had induced the formation of spheroplasts in causing lysis of $\boldsymbol{E}$. coli and other Gram-negative species by treatment with lysozyme and EDTA. Actually, Repaske (1956, 1958), Mahler \& Fraser (1956), and Fraser \& Mahler (1957) never reported the production of spheres from rods; their observations were confined to the occurrence of lysis. It may be that, under their conditions 
and with their strains, spheroplasts were produced; however, this does not appear to have been established.

Murti (1960) has, indeed, shown the production of spheres from Escherichia coli and Vibrio cholerae under the influence of lysozyme and EDTA in buffered sucrose solution; however, incubation for $2-3 \mathrm{hr}$ at $38^{\circ}$ was required for this transformation. The observations of Repaske and of Mahler \& Fraser, as well as those reported above, concern changes occurring within the first few minutes at room temperature. Continuation of these changes might well be expected to lead to the eventual loss of rigidity of the cell wall and the formation of spheroplasts.

The results reported here show that a stage intermediate between the intact cell and the spheroplast exists. In these cases, damage to the cell wall was sufficient to cause it to lose its effectiveness as a rigid support for the cytoplasmic membrane, but was still so incomplete that the characteristic shape of the organism was not lost. This may well be the case in other work in which osmotic fragility has been assumed to demonstrate conversion of cells into spheroplasts.

The evidence of some degree of damage to the cell wall by exposure to the system containing only EDTA and tris buffer is in agreement with the data reported by Repaske (1956, 1958), who showed significant lysis of Pseudomonas aeruginosa by EDTA in the absence of lysozyme. It is assumed that this action of buffered EDTA on the cell wall, causing some morphological evidence of damage and some lysis, is that which causes the cell wall to become susceptible to lysozyme.

Thanks are due to Mr A. P. Murphy for electron microscopy and photography.

\section{REFERENCES}

Brenner, S., Dark, F. A., Gerhardt, P., Jeynes, M. H., Kandler, O., Kelienberger, E., Klieneberger-Nobel, E., McQuillen, K., Rubio-Huertos, M., Salton, M. R. J., Strange, R. E., Tomcsik, J. \& Weibull, C. (1958). Bacterial protoplasts. Nature, Lond. 181, 1713.

Chapman, G. B. (1959). Electron microscopy of ultrathin sections of bacteria. III. Cell wall, cytoplasmic membrane, and nuclear material. J. Bact. 78, 96.

Fraser, D. \& Mahler, H. R. (1957). The effects of nucleases on the reproduction of T3 bacteriophage in protoplasts of Escherichia coli. Archs. Biochem. Biophys. 69, 166.

MAfler, H. R. \& Fraser, D. (1956). Reproduction of bacteriophage T3 in protoplasts of Escherichia coli, strain B. Biochim. biophys. Acta, 22, 197.

McQuillen, K. (1958). Bacterial 'protoplasts': effects of diaminopimelic acid deprival and penicillin addition compared in Escherichia coli. Biochim. biophys. Acta, $27,410$.

McQumlen, K. (1960). Bacterial protoplasts; in The Bacteria. A Treatise on Structure and Function. Ed. by I. C. Gunsalus \& R. Y. Stanier, vol. 1, p. 268. New York and London: Academic Press.

Murti, C. R. K. (1960). Preparation of bacterial enzymes by controlled lysis. Biochim. biophys. Acta, 45, 243.

REPASke, R. (1956). Lysis of Gram-negative bacteria by lysozyme. Biochim. biophys. Acta, 22, 189.

REPASKE, R. (1958). Lysis of Gram-negative organisms and the role of Versene. Biochim. biophys. Acta, 30, 225.

Tulasne, R., Mrnck, R., Kirn, A. \& Krembel, J. (1960). Délimitation de la notion de formes L des bactéries: protoplastes, sphéroplastes et formes L. Ann. Inst. Pasteur, $99,859$.

Zinder, N. D. \& Arndt, W. F. (1956). Production of protoplasts of Escherichia coli by lysozyme treatment. Proc. nat. Acad. Sci., Wash. 42, 586. 
Journal of General Microbiology, Vol. 35, No. 2

Plate 1
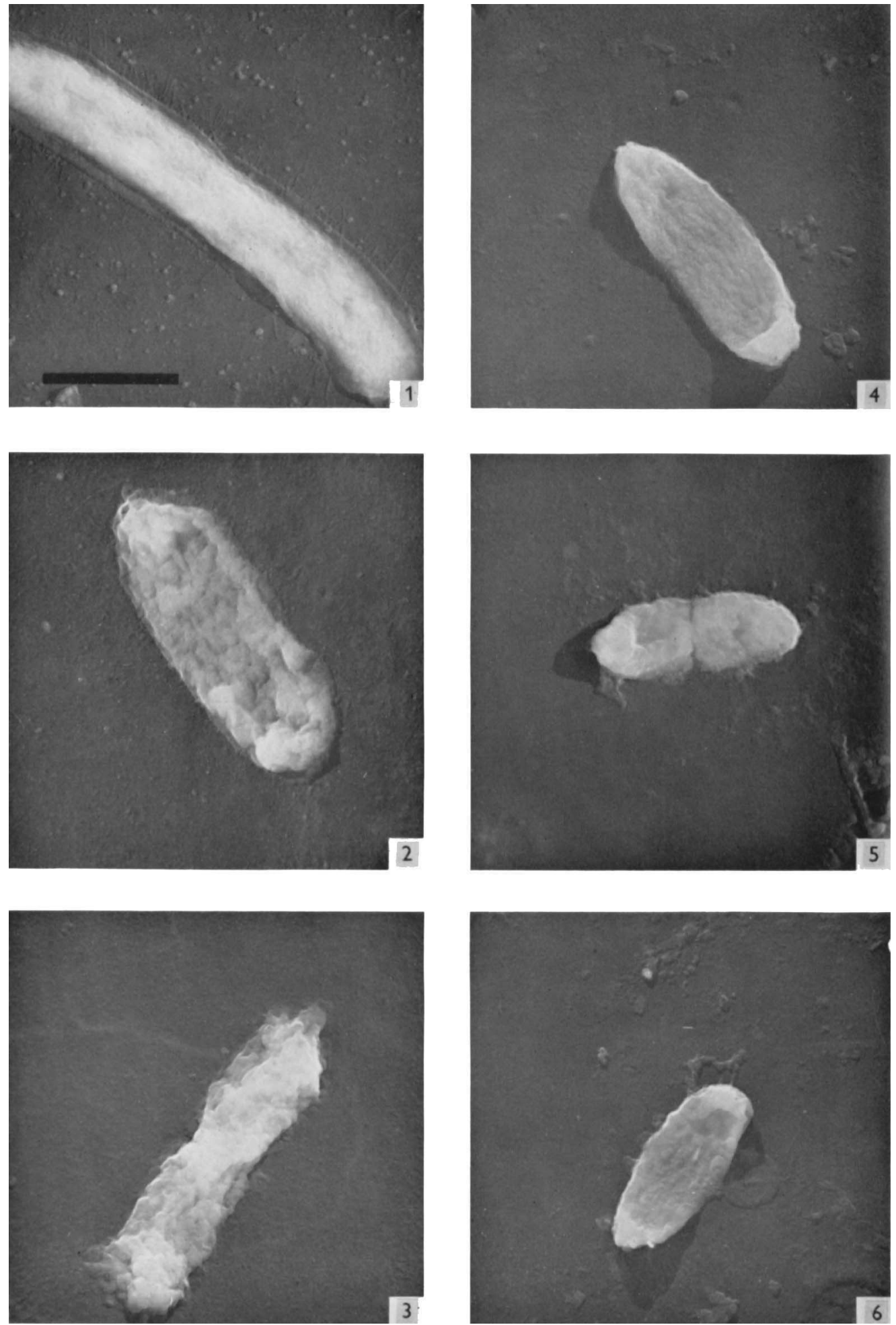

J. G Voss

(Facing $n$. 317) 


\section{EXPLANATION OF PLATE}

Electron micrographs of platinum-shadowed Escherichia coli and Pseudomonas aeruginosa are all at the same magnification; the mark on Fig. 1 represents 1 micron. Cells fixed with osmic acid and washed.

Fig. 1. Escherichia coli after exposure to $0.5 \mathrm{~m}$-sucrose.

Fig. 2. Escherichia coli treated with EDTA and tris buffer in the presence of $0.5 \mathrm{M}$-sucrose.

Fig. 3. Escherichia coli treated with lysozyme, EDTA, and tris buffer in the presence of $0.5 \mathrm{M}$ sucrose.

Fig. 4. Pseudomonas aeruginosa after exposure to 0.5 M-sucrose.

Fig. 5. Pseudomonas aeruginosa treated with EDTA and tris buffer in the presence of $0.5 \mathrm{~m}$-sucrose.

Fig. 6. Pseudomonas aeruginosa treated with lysozyme, EDTA, and tris buffer in the presence of 0.5 M-sucrose. 